\title{
Production of lactic acid by Lactobacillus paracasei isolated from button mushroom bed
}

\author{
Sun-Joong Kim ${ }^{1}$, Hye-Kyung Seo ${ }^{1}$, Won-Sik Kong ${ }^{2}$ and Min-Ho Yoon ${ }^{1 *}$ \\ ${ }^{\text {I} D e p a r t m e n t ~ o f ~ B i o-E n v i r o n m e n t a l ~ C h e m i s t r y, ~ C h u n g n a m ~ N a t i o n a l ~ U n i v e r s i t y, ~} 99$ Daehak-Ro, Yusung-Gu, \\ Daejeon 305-764, Republic of Korea \\ ${ }^{2}$ Mushroom Research Division, National Institute of Horticultural \& Herbal Science, RDA, Eumseong, Chungbuk, 369-873, Korea.
}

(Received November 18, 2013 / Revised December 27, 2013 / Accepted December 31, 2013)

\begin{abstract}
A galactose fermentation bacterium producing lactose from red seaweed, which was known well to compromise the galactose as main reducing sugar, was isolated from button mushroom bed in Buyeo-Gun, Chungchugnamdo province. The lactic acid bacteria MONGB-2 was identified as Lactobacillus paracasei subsp. tolerans by analysis of $16 \mathrm{~S}$ rRNA gene sequence. When the production of lactic acid and acetic acid by L. paracasei MONGB-2 was investigated by HPLC analysis with various carbohydrates, the strain MONGB-2 efficiently convert the glucose and galactose to lactic acid with the yield of $18.86 \mathrm{~g} / \mathrm{L}$ and $18.23 \mathrm{~g} / \mathrm{L}$, respectively and the ratio of lactic acid to total organic acids was 1.0 and $0.91 \mathrm{~g} / \mathrm{g}$ for both substrates. However, in the case of acetic acid fermentation, other carbohydrates besides galactose and red seaweed hydrolysate could not be totally utilized as carbon sources for acetic acid production by the strain. The lactic acid production from glucose and galactose in the fermentation time courses was gradually enhanced upto $60 \mathrm{~h}$ fermentation and the maximal concentration reached to be $16-18 \mathrm{~g} / \mathrm{L}$ from both substrates after $48 \mathrm{~h}$ of fermentation. The initial concentration of glucose and galactose were completely consumed within $36 \mathrm{~h}$ of fermentation, of which the growth of cell also was maximum level. In addition, the bioconversion of lactic acid from the red seaweed hydrolysate by $L$. paracase i MONGB-2 appeared to be about $20 \%$ levels of the initial substrates concentration and this results were entirely lower than those of galactose and glucose showed about $60 \%$ of conversion. The apparent results showed that L. paracasei MONGB-2 could produce the lactic acid with glucose as well as galactose by the homofermentation through EMP pathway
\end{abstract}

KEYWORDS - Fermentations, Galactose, Lactic acid, Lactobacillus paracasei, Red Seaweed

\section{Introduction}

Lactic acid is an important industrial chemical with wide applications in the food, pharmaceutical, leather, and cosmetic industries (Datta et al., 1995; Garde et al., 2002; Lunt, 1998; Passos et al., 1994). Since lactic acid has high reactivity due to containing both hydroxyl (-OH) and carboxyl (-COOH) groups, it plays a major role as a chemical feedstock capable of being converted to various chemicals such as acrylic acid, propylene glycol, acetaldehyde, and 2,3-pentanedione (Varadarajan and Miller, 1999). Lactic acid is industrially produced either by chemical synthesis or by microbial fermentation. A biological method has the advantage that an optically pure lactic acid can be obtained by choosing a strain of lactic acid bacteria, whereas chemical synthesis always results in a racemic mixture of lactic acid
(Ryu et al., 2003). The presence of L(+)-lactic acid with high optical purity gives polylactic acids of high melting point and high crystallinity (Lunt, 1998; Yun and Ryu, 2001).

Refined sugars such as glucose or sucrose have been more frequently used to produce lactic acid than raw starchy substrates such as barley, corn, or wheat (Hofvendahl and Hahn-Hägerdal, 1997). Furthermore, a considerable amount of expensive complex nitrogen source, such as yeast extract, must be added to the medium to produce lactic acid in a reasonable time. However, these are economically unfavorable because pure sugars and pure complex nitrogen sources are expensive but lactic acid is a relatively cheap product. Therefore, raw materials for industrial lactic acid production need to have several characteristics such as low cost, low levels of contaminants, rapid fermentation rate, high lactic

*Corresponding author: mhyoon@cnu.ac.kr 
acid yields, little or no by-product formation, and yearround availability (Ryu et al., 2003).

The selection of suitable raw materials is an effective approach to reduce the cost involved in the production of lactic acid. Recently, seaweeds are drawing attention as the "third generation biomass", as their cultivation on non-arable land requires no encroachment on cropland used to produce food, and their low lignocellulose content lowers the effort and cost required for pretreatment. For these reasons, red seaweed is currently being considered as a potential resource of biomass-based chemicals and biofuels (Roesijadi et al., 2010).

Although many studies on the production of biofuels from seaweed have been reported, thus far there are only a few studies about lactic acid production from seaweeds (Uchida, 2005). In this study, we reported on the isolation of a lactic acid producing bacteria and the results of lactic acid fermentation produced by the isolated strain using either various reducing sugars such as glucose and galactose or the red seaweed hydrolysate as renewable biomass.

\section{Materials and Methods}

\section{Isolation of lactic acid producing bacteria}

The lactic acid producing bacteria (LAB) were isolated from button mushroom bed in Buyeo-Gun, Chungchugnam-do province. Serially diluted aliquots of button mushroom bed samples were inoculated in Lactobacilli MRS(Difco, Detroit, USA) broth containing $1 \%$ galactose and grown for $48 \mathrm{~h}$ at $36^{\circ} \mathrm{C}$. Lactic acid content in the supernatants after incubation was measured by HPLC analysis to select LABs.

\section{Cultivation of LABs}

The preculture of selected LABs was grown stationary at $36^{\circ} \mathrm{C}$ for $72 \mathrm{~h}$ in the lactic acid producing medium as follows: yeast extract $5.5 \mathrm{~g} / \mathrm{L}$, peptone $12.5 \mathrm{~g} / \mathrm{L}$, $\mathrm{KH}_{2} \mathrm{PO}_{4} 0.25 \mathrm{~g} / \mathrm{L}, \mathrm{K}_{2} \mathrm{HPO}_{4} 0.25 \mathrm{~g} / \mathrm{L}, \mathrm{CH}_{3} \mathrm{COONa} 10 \mathrm{~g} / \mathrm{L}$, $\mathrm{MgSO}_{4} 0.1 \mathrm{~g} / \mathrm{L}$ and carbon sources for the production of lactic acid were added with to galactose of $30 \mathrm{~g} / \mathrm{L}$, $40 \mathrm{~g} / \mathrm{L}, 50 \mathrm{~g} / \mathrm{L}$, respectively. Galactose as a carbon source was replaced with glucose, fructose, maltose, xylose, glycerol and red seaweed hydrolysate to evaluate the effects of various carbon sources on lactic acid fermentation. The culture broth at given cultivation times was withdrawn every $12 \mathrm{~h}$ from the fermentation medium and filtered with $0.45 \mu \mathrm{m}$ of cellulose acetate filter for HPLC analysis.

Saccharification of red seaweed by acid hydrolysis. Red seaweed was thoroughly washed to remove salt and then dried in an dry oven at $50^{\circ} \mathrm{C}$. After drying, the seaweed was milled to less than a 100mesh size using a food mixer. For saccharification of red seaweed, the hydrolysis reaction of $30 \mathrm{~g} / \mathrm{L}$, $40 \mathrm{~g} / \mathrm{L}$ and $50 \mathrm{~g} / \mathrm{L}$ seaweed was conducted for $15 \mathrm{~min}$ at $121^{\circ} \mathrm{C}$ using $3 \%(\mathrm{v} / \mathrm{v}) \mathrm{H}_{2} \mathrm{SO}_{4}$ as a catalyst. After hydrolysis, the mixture was neutralized with $10 \%(\mathrm{v} / \mathrm{v}) \mathrm{NH}_{4} \mathrm{OH}$ and centrifuged at $8000 \mathrm{rpm}$ for $10 \mathrm{~min}$ to remove the precipitated salt (Jang et al., 2012). The supernatant was filtered with $0.45 \mu \mathrm{m}$ of cellulose acetate filter and used for assessment of reducing sugars by HPLC.

\section{Analysis of organic acids}

The amount of organic acids such as lactic acid and acetic acid was determined using HPLC system(Agilent series 1100, USA). The used column was Inertsil ODS-3V column $(3.0 \times 150 \mathrm{~mm}, 5 \mu \mathrm{m}$, GL Sciences Inc., Japan) at $40^{\circ} \mathrm{C}$ with UV detector $(210 \mathrm{~nm})$. The mobile phase was $0.008 \mathrm{~N} \mathrm{H}_{2} \mathrm{SO}_{4}$ at flow rate of $0.3 \mathrm{ml} / \mathrm{min}$. The sample were filtered with $0.45 \mu \mathrm{m}$ of cellulose acetate filter and $10 \mu \mathrm{l}$ of the filtrate was injected. HPLC profiles of the culture filtrate was analyzed by comparison with the elution profiles of those of authentic standards organic acids injected separately.

\section{Analysis of reducing sugars}

The concentration of reducing sugars, glucose, fructose, maltose, and xylose, were determined by DNSA method (Miller, G. L., 1954 ). In addition, to estimate the ratio of reducing sugar converted to lactic acid, the concentrations of galactose and glucose used as carbon sources, were measured by the Bio-LC (HPAEC-PAD) system (Dionex, USA) 
at Sejong University Carbohydrate Bioproduct Research Center (Soeul, Korea). The CarboPac ${ }^{\mathrm{TM}}$ PA1 column $(4 \times 250 \mathrm{~mm}$, Dionex, USA $)$ at room temperature with ED50 Electrochemical detector was used. The mobile phase was $18 \mathrm{mM} \mathrm{NaOH}$ at flow rate of $1 \mathrm{ml} / \mathrm{min}$. The sample were filtered with $0.20 \mu \mathrm{m}$ of filter and $50 \mu \mathrm{l}$ of injection volume was added.

\section{Identification of the selected strain}

The partial sequencing of 16S rRNA for the bacterial strains was done with the help of DNA sequencing service, SOLGENT, Daejeon, South Korea using universal primers, 27F (5'AGAGTTTGATCCTGGCTCAG-3') and 1492R (5'GGTTACCTTGTTACGACTT-3'). The online program BLAST was used in identifying the related sequences with known taxonomic information available at the databank of NCBI (http://www.ncbi.nlm.nih.gov/ BLAST). A phylogenetic tree was constructed using CLUSTAL X program (Thompson et al., 1997), which involved sequence alignment by neighbor joining method (Saitou and Nei, 1987) and maximum parsimony using the MEGA4 program (Kumar et al., 2001). Grouping of sequences was based on confidence values obtained by bootstrap analysis of 1,000 replicates. Gaps were edited in the BioEdit program and evolutionary distances were calculated using Kimura two parameter model. Reference sequences were retrieved from GenBank under the accession numbers indicated in the trees.

\section{Results}

\section{Isolation of lactic acid producing bacteria}

Seven of the lactic acid producing bacteria (LAB) which convert galactose as carbon source to lactic acid, were isolated from button mushroom bed in Buyeo-Gun, Chungchugnam-do province, South Korea. Lactic acid fermentation of the selected strains using various substrates was conducted through $50 \mathrm{ml}$ of Erlenmeyer flask incubation with the basal medium containing $30 \mathrm{~g} / \mathrm{L}$ of glucose, and red seaweed hydrolysate. When lactic acid content produced by the strains after $36 \mathrm{~h}$ incubation was
Table 1. Lactic acid produced by the selected strains with different substrates

\begin{tabular}{cccc}
\hline \multirow{2}{*}{ Strain } & \multicolumn{3}{c}{ Lactic acid concentration (g/L) ${ }^{\mathrm{a}}$} \\
\cline { 2 - 4 } & $\begin{array}{c}3 \% \\
\text { Glucose }\end{array}$ & $\begin{array}{c}3 \% \\
\text { Galactose }\end{array}$ & $\begin{array}{c}\text { Red seaweed } \\
\text { (3\% }\end{array}$ \\
& Sulfuric hydrolysate) \\
\hline L. acidophilus & 13.24 & ND & ND \\
MONGB-2 & 18.18 & 17.56 & 7.54 \\
JG-2 & 8.94 & ND & ND \\
MALB-2 & 16.67 & 12.53 & 4.87 \\
NMONG-2 & 17.25 & 13.74 & 3.24 \\
ZAL & 18.07 & 14.66 & 5.69 \\
ZIL & 15.39 & 16.14 & 4.24 \\
\hline
\end{tabular}

${ }^{\mathrm{a}}$ The fermentations were conducted in a $50 \mathrm{ml}$ flask incubation with the carbohydrates concentration of $30 \mathrm{~g} / \mathrm{L}$ at $36^{\circ} \mathrm{C}$ and grown stationary for $36 \mathrm{~h}$.

measured by HPLC analysis, the isolate MONGB-2 appeared to produce the highest amount of lactic acid among all selected strains as $18.18 \mathrm{~g} / \mathrm{L}$ for glucose and $17.56 \mathrm{~g} / \mathrm{L}$ for galactose, whereas the red seaweed hydrolysate was poorly converted to lactic acid by all strains, respectively (Table 1). The strain MONGB-2 was finally selected for further studies, based on the results of lactic acid producing ability.

\section{Identification of strain MONGB-2}

According to $16 \mathrm{~S}$ rRNA sequence analysis, the strain MONGB-2 showed close proximity with Lactobacillus paracasei subsp. tolerans. Phylogenetic tree shows the position of isolated bacterial strain with respect to the related species .

\section{Lactic acid production from different carbohydrates}

Lactic acid fermentation of the $L$. paracasei MONGB-2 using various substrates was conducted through $50 \mathrm{ml}$ of Erlenmeyer flask incubation with $30 \mathrm{~g} / \mathrm{L}$ of carbohydrates and the results were shown in Table 2. The strain MONGB-2 showed the different fermentation characterization with the respective carbohydrates. When the basal medium containing glucose, galactose, fructose, maltose, xylose or red seaweed hydrolysate was used as carbon sources, L. paracasei MONGB-2 efficiently convert the glucose and galactose to lactic acid with the yield of $18.86 \mathrm{~g} / \mathrm{L}$ and $18.23 \mathrm{~g} / \mathrm{L}$ and the ratio of 
Table 2. Effect of difference carbohydrates on organic acids production in Lactobacillus paracasei MONGB-2 fermentation $^{\mathrm{a}}$

\begin{tabular}{cccc}
\hline \multirow{2}{*}{ Carbon sources } & \multicolumn{3}{c}{ Organic acids $(\mathrm{g} / \mathrm{L})$} \\
\cline { 2 - 4 } & Lactic acid & Acetic acid & $Y_{\text {LA/TA }}(\%)^{\mathrm{c}}$ \\
\hline None & 1.12 & $\mathrm{ND}^{\mathrm{b}}$ & 100 \\
Glucose & 18.86 & $\mathrm{ND}$ & 100 \\
Galactose & 18.23 & 2.25 & 89 \\
Maltose & 14.79 & $\mathrm{ND}$ & 100 \\
Frcutose & 15.42 & $\mathrm{ND}$ & 100 \\
Xylose & 1.57 & $\mathrm{ND}$ & 100 \\
Red seaweed & 7.58 & 1.34 & 84.9 \\
\hline
\end{tabular}

${ }^{a}$ The fermentations were conducted in a $50 \mathrm{ml}$ flask incubation with the carbohydrates concentration of $30 \mathrm{~g} / \mathrm{L}$ at $36^{\circ} \mathrm{C}$ and grown stationary for $36 \mathrm{~h}$.

${ }^{\mathrm{b}}$ Not detected

${ }^{\mathrm{c}}$ Gram of lactic acid/gram of total organic acid $\times 100$

lactic acid to total organic acids was 1.0 and $0.89 \mathrm{~g} / \mathrm{L}$, respectively. However, in the case of acetic acid fermentation, other carbohydrates besides galactose and red seaweed hydrolysate could not be totally utilized as carbon sources for acetic acid production by the strain MONGB-2. Generally the homofermentative lactic acid bacteria could metabolized the carbohydrates into lactic acid as a major end product through EMP pathway, while the heterofermentative lactic acid bacteria could utilize the pentose sugar such as xylose through pentose-phosphate pathway. The apparent results showed that $L$. paracasei MONGB-2 could produce the lactic acid with glucose as well as galactose by the homofermentation through EMP pathway and the optimal carbon sources for the lactic acid fermentation were confirmed to be glucose and galactose.

\section{Lactic acid production from glucose or galactose}

Lactic acid production by $L$. paracasei MONGB-2 was investigated with $30 \mathrm{~g} / \mathrm{L}$ of glucose and galactose in the time course for $72 \mathrm{~h}$. As shown in Fig. 2, the lactic acid production was gradually enhanced upto $60 \mathrm{~h}$ fermentation and the maximal concentration reached to be $16-18 \mathrm{~g} / \mathrm{L}$ from both substrates after $48 \mathrm{~h}$ of fermentation. The initial concentration of glucose and galactose were completely consumed within $36 \mathrm{~h}$ of fermentation, at the time of which the growth of cell also was maximum level. Even though the lactic acid concentration from glucose was a little higher than that of galactose, the strain could efficiently utilize the galactose as a carbon source for lactic acid production unlike other lactic acid bacteria reported so far (Yun and Ryu, 2001). The galactose fermentation bacteria could be enough useful for lactic acid or other organic acids production using the red

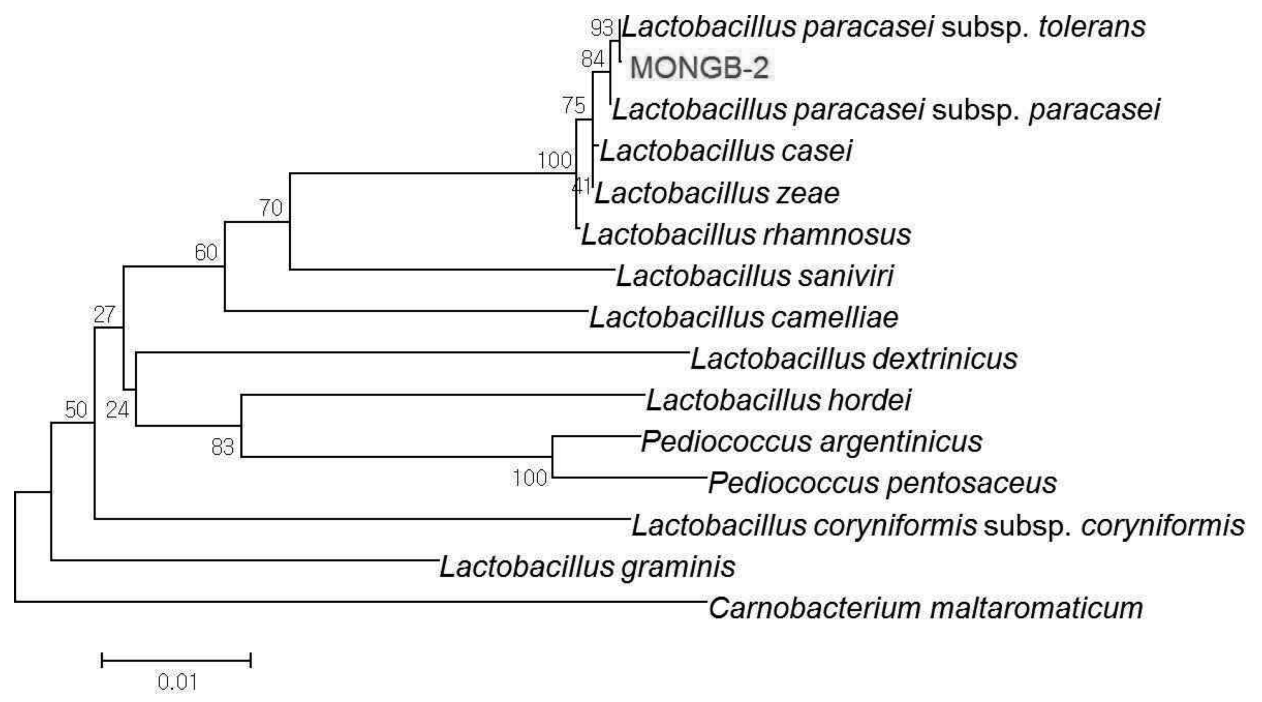

Fig. 1. Phylogenetic relationships of the isolate MONGB-2 and other closely related bacteria by the partial 16S rDNA sequence. The branching pattern was generated by the neighbor-joining method. Bootstrap values (expressed as percentages of 10,000 replications) are shown at major branching points. Bar, 0.01 substitution per nucleotide position. 

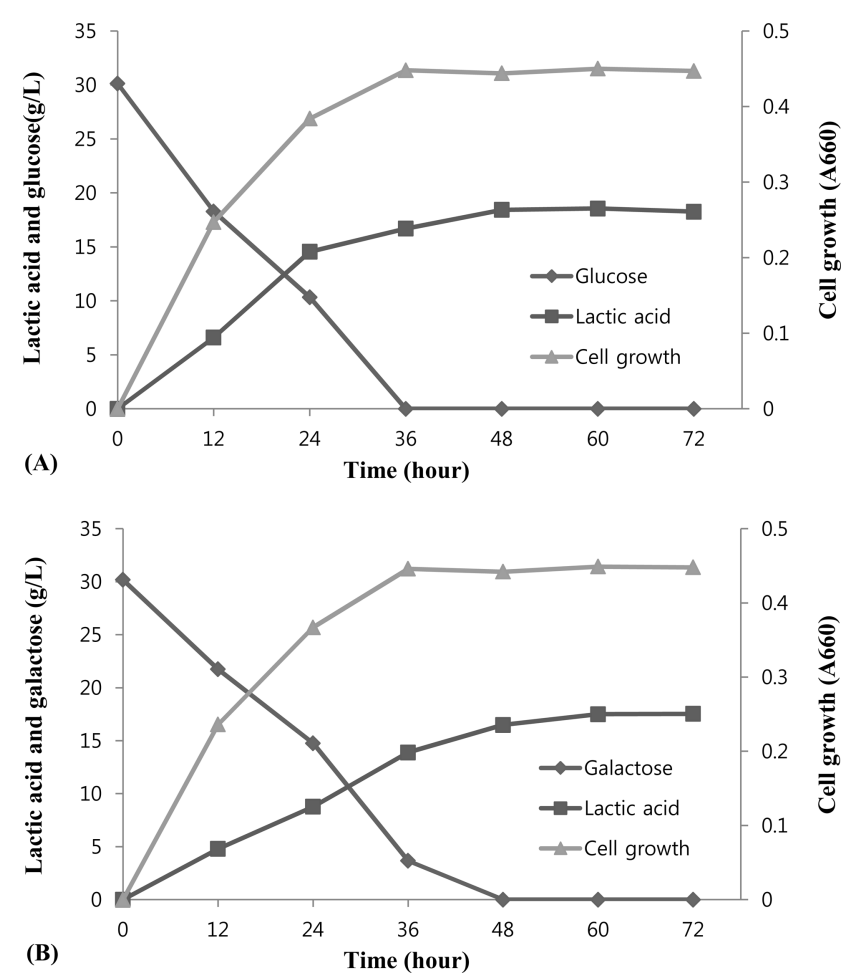

Fig. 2. Profile of lactic acid fermentation from glucose (A) and galactose (B) by Lactobacillus paracasei subsp. tolerans. The fermentations were conducted $500 \mathrm{ml}$ Erlenmeyer flask and incubated stationary at $36^{\circ} \ldots$ for 3 days.

seaweed known well as one of the representative biomass resources. However, the lactic acid production of the strain MONGB-2 was rather to be inhibited at the high concentration of reducing sugars such as $40 \mathrm{~g}$ or $50 \mathrm{~g} / \mathrm{L}$ of galactose and glucose, in the concentration of which the cells also were seldom grown and the carbohydrates has not completely consumed (data not shown). This result suggested that the rate and yield of the lactic acid production by $L$. paracasei MONGB-2 may be affected by the reduction of sugars like other lactic acid producing bacteria (Gao et al., 2005).

\section{Lactic acid production from red seaweed hydrolysate}

Red seaweed hydrolysate which compromises galactose and glucose as main reducing sugars was used for evaluating the influence of the concentration containing 3\%, 4\% and $5 \%$ of red seaweed hydrolysate on lactic acid fermentation in the time course for $72 \mathrm{~h}$. As shown in Fig. 3, the

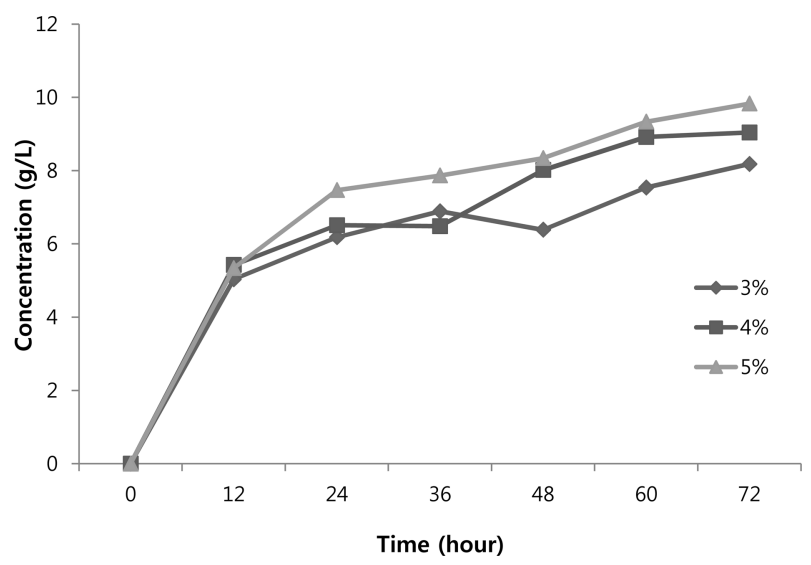

Fig. 3. Lactic acid production in lactic acid fermentation with red seaweed hydrolysate by Lactobacillus paracasei subsp. tolerans. The fermentations were conducted $500 \mathrm{ml}$ Erlenmeyer flask and incubated stationary at $36^{\circ} \mathrm{C}$ for 3days.

lactic acid production for $72 \mathrm{~h}$ of fermentation was gradually enhanced with the increase of the initial red seaweed concentration up to $5 \%$ and the maximum lactic acid concentration reached to be 6.1, 6.6, and 7.2 $\mathrm{g} / \mathrm{L}$ for $3 \%, 4 \%$ and $5 \%$ substrates after $36 \mathrm{~h}$ of fermentation, respectively. The bioconversion of lactic acid from the red seaweed hydrolysate by $L$. paracasei MONGB-2 was about $20 \%$ levels of the initial substrates concentration and this results were entirely lower than those of galactose and glucose, which showed about $60 \%$ of conversion. The red seaweed hydrolysate which was prepared by sulfuric acid hydrolysis may be containing various components such as oligosacharides and acid residues besides the reducing sugars and their byproducts could be affected as the inhibitors of lactic acid fermentation. That can be considered to explain why the yield of the lactic acid produced from the red seaweed hydrolysate is very low, compare to those of galactose and glucose.

\section{Discussion}

Lactic acid producing bactria(LAB) are known to use more easily the refined sugars such as glucose or sucrose than raw starchy substrates such as barley, corn, or wheat for lactic acid production (Hofvendahl and Hahn-Hägerdal, 1997). However, it 
was rarely reported that a bacteria producing the lactic acid using galactose or sea weed as a carbon source. Therefore, it is worth to isolate and screen the microorganisms for producing lactic acid with a raw substrate composed to the galactose polymer like seaweed. In the present study, the LABs were isolated from the button mushroom bed and screened by evaluating their lactic acid production through HPLC analysis. Based on the results of lactic acid production, one strain with outstanding performances was selected for further studies. The strain was identified as Lactobacillus paracasei subsp. tolerans by the 16S rRNA sequence analysis. There were some previous reports about Lactobacillus spp. as efficient lactic acid producers (Garde et al., 2002: Gao et al., 2005), but most of them were obtained with other carbohydrates such as glucose and sucrose besides galactose as carbon sources.

As reported previously, the production of lactic acid could be appeared to be different by using the general mediums with different carbohydrates $(\mathrm{Oh}$ et al., 2005; Uchida, 2005). When the yield of lactic acid by $L$. paracasei MONGB-2 was evaluated with various substrates, a significant positive correlation was observed between lactic acid production and bacterial growth according to carbon sources. The stationary phase of the cell growth in glucose and glactose began to appear $36 \mathrm{~h}$ after the commencement of the incubation. Lactic acid production was found to reach the maximum at the stationary phase of the growth, which is analogous to (Jang et al., 2013) who also observed the maximum lactic acid production during stationary phase of the growth. $L$. paracasei MONGB-2 produced the lactic acid as a major end product with glucose as well as galactose by the homofermentation through EMP pathway, while it was rarely grown in the medium containing xylose, suggesting the strain could not utilize the pentose sugar such as xylose through pentosephospahate pathway. Consequently, galactose and glucose at $30 \mathrm{~g} / \mathrm{L}$ is the best concentration for the maximum production of lactic acid. In concentrations over $40 \mathrm{~g} / \mathrm{L}$ of reducing sugars decreased lactic acid production by the strain. Unlike galactose showed about $60 \%$ of conversion, the strain converted the red seaweed hydrolysate into lactic acid with about $20 \%$ levels of the intial substrates concentration. The slight decrease in lactic acid production on the respective concentrations of red seaweed hydrolysate may be due to the byproducts of sulfuric acid hydrolysis in the culture medium, which has an inhibitory effect on lactic acid fermentation by the selected LAB (Jang et al., 2013).

The findings of the present investigation highlighted that the isolated strain has great potential to enhance the production of lactic acid with galactose or red seaweed through the galactose fermentation. However, the assessment of lactic acid producing characteristics and further studies under conditions using more refined seaweed hydrolysate would be ideal in confirming the present findings and also in recommending the strains as lactic acid producer.

\section{Acknowledgements}

This study was supported by a grant from the research project(No. PJ0067492011) of National Institute of Horticultural \& Herbal Science, Rural Development Administration, Republic of Korea.

\section{References}

Datta, R., Tsai, S.P., Bonsignore, P., Moon, S.H. and Frank, J.R. 1995. Technological and economic-potential of poly(lactic acid) and lactic acid derivatives. FEMS Microbiol. Rev. 16 : 221-231.

Gao, M.T., Koide, M., Gotou, R., Takanashi, H., Hirata, M. and Hano, T. 2005. Development of a continuous electrodialysis fermentation system for production of lactic acid by Lactobacillus rhamnosus, Process Biochem. 40 : 1033-1036.

Garde, A., Jonsson, G., Schmidt, A.S. and Ahring, B.K. 2002. Lactic acid production from wheat straw hemicellulose hydrolysate by Lactobacillus pentosus and Lactobacillus brevis. Bioresour. Technol. 81 : 217-223.

Hofvendahl, K. and Hahn-Hägerdal, B. 1997. L-Lactic acid production from whole wheat flour hydrolyzate using strains of Lactobacilli and Lactococci, Enzyme Microb. Technol. 20 : 301-307.

Jang, S. S., Shrai, Y., Uchida, M. and Wakisaka, M. 2012. Production of mono sugar from acid hydrolysis of seaweed. African J. Biotechnol. 11 : 1953-1963.

Jang, S.S., Shrai, Y., Uchida, M. and Wakisaka, M. 2013. Potential use of Gelidium amansii acid hydrolysate for 
lactic acid production by Lactobacillus rhamnosus. Food Technol. Biotechnol. 51 : 131-136.

Kumar, S., K., Tamura, I. Jakobsen, B., and Nei, M. 2001. MEGA2: molecular evolutionary genetics analysis software. Bioinformatics. $17: 1244-1245$.

Lunt, J. 1998. Large-scale production, properties and commercial applications of polylactic acid polymers. Polym. Degrad. Stabil. 59 : 145-152.

Miller, G. L. 1954. Use of dinitrosalysilic acid reagent for determination of reducing sugar. Anal. Chem. 31:426-428.

Oh, H., Wee, Y. J., Yun, J. S., Han, S. H., Jung, S. W. and Ryu, H. W. 2005. Lactic acid production from agricultural resources as cheap raw materials. Bioresour. Technol. 96 : 1492-1498.

Passos, F.V., Fleming, H.P., Ollis, D.F., Felder, R.M. and Mcfeeters, R.F. 1994. Kinetics and modeling of lactic-acid production by Lactobacillus plantarum. Appl. Environ. Microbiol. 60 : 2627-2636.

Roesijadi, G., Jones, S.B., Snowden-Swan, L.J., and Zhu, Y. 2010. Macroalgae as a biomass feedstock: A Preliminary Analysis, PNNL 19944.
Ryu, H.W., Yun, J.S. and Wee, Y.J. 2003. Lactic acid, pp. 635. In: Pandey, A.(Ed.), Concise Encyclopedia of Bioresource Technology. The Haworth press: New York, The USA.

Saitou, N. and Nei, M. 1987. The neighbor-joining method: a new method for reconstructing phylogenetic trees. Mol. Biol. Evol. 4 : 406-425.

Thompson, J.D., Gibson, T.J., Plewniak, F., Jeanmougin, F., and Higgins, D.G. 1997. The CLUSTAL X windows interface: flexible strategies for multiple sequence alignment aided by quality analysis tools. Nucleic Acids Res. 25 : 4876-4882.

Uchida, M. 2005. Studies on lactic acid fermentation of seaweed. Bull. Fish. Res. Agency. 14 : 21-85

Varadarajan, S. and Miller, D.J. 1999. Catalytic upgrading of fermentation-derived organic acids. Biotechnol. Prog. 15 : 845-854.

Yun, J.S. and Ryu, H.W. 2001. Lactic acid production and carbon catabolite repression from single and mixed sugars using Enterococcus faecalis RKY1. Proc. Biochem. 37 : 235-240. 